\title{
Knowledge and perception of genetically modified foods among medical doctors of Jos University Teaching Hospital Jos, Nigeria
}

Daboer $\mathrm{JC}^{1}$, Zaman $\mathrm{M}^{2}$, Birdling $\mathrm{NN}^{2}$, Maigamo $\mathrm{NY}^{2}$, Orya $\mathrm{EE}^{2}$, Idogho $\mathrm{J}^{2}$, Tagurum $\mathrm{YO}^{1}$, Banwat $\mathrm{ME}^{1}$, Akosu, $\mathrm{TJ}^{1}$, Chingle $\mathrm{MP}^{1}$ and Zoakah $\mathrm{AI}^{1}$.

${ }^{1}$ Department of Community Medicine, College of Health Sciences, University of Jos, Nigeria

${ }^{2}$ Department of Community Medicine, Jos University Teaching Hospital, Jos, Nigeria

Correspondence: Daboer J.C: jonathandabor@yahoo.co.uk

\begin{abstract}
Background: The use of genetically modified foods and organisms has continued to gain popularity globally, especially in the areas of improved food security and medical research. However, the global acceptance and consumption of these foods are marred by skepticism and controversy due to concerns about their long term health and environmental effects. This study was undertaken to assess the knowledge and perception of genetically modified foods among medical doctors of the Jos University Teaching Hospital in Nigeria.

Methods: A cross-sectional study was conducted in May 2018 among 230 medical doctors who were selected using a stratified sampling technique. Data were collected using a semi-structured self-administered questionnaire and analyzed using the Statistical Package for Social Sciences version 23.

Results: Only 19.5\% of the 230 respondents were found to have good knowledge of genetically modified foods, while $87 \%$ expressed concerns related to possible health risks from the consumption of these foods. A low proportion (31.7\%) of the respondents indicated willingness to consume genetically modified foods.

Conclusion: There was a low level of knowledge of genetically modified foods, heightened concerns about possible adverse health risks associated with their consumption and a low willingness to consume such foods among medical doctors in the Jos University Teaching Hospital. Therefore, there is the need to further educate doctors on the benefits and safety of genetically modified foods.
\end{abstract}

Key words: Knowledge, Perception, Genetically modified, foods, doctors

\section{Introduction}

Modern biotechnology has enabled the deliberate alteration of the genetic composition of living organisms. ${ }^{1}$ Genetically Modified Organisms (GMOs) are plants, animals or microorganisms produced through alteration in their genetic material in a manner that does not occur naturally and in order to achieve a predetermined useful purpose. ${ }^{2,3}$ Food items produced using GMOs are termed Genetically Modified (GM) foods. This technology has led to large scale production of many food crops in the USA, Argentina, Brazil, Canada and India., In Africa, the acceptance of GM foods has been rather slow. ${ }^{6}$

Genetically modified foods have been a source of protracted debate as a result of concerns regarding their safety to the 
environment, human health and effect on biodiversity. ${ }^{1,2}$ Human health concerns about GM foods are related to their potentials to cause genetic mutations, allergic reactions and toxicity. In countries where the technology is deeply entrenched, the advent of GM foods has produced enormous benefits for the farmers and consumers in terms of efficient crop production, higher yields, improved resistance to pests, enhanced nutritional value and lower price. ${ }^{1,45}$ However, these benefits have not eroded safety concerns about the product among members of the public. Since these potential risks are scientifically plausible, they are being investigated through researches and continuous product monitoring. ${ }^{1,6}$

Fears on GM food safety are largely fuelled by ignorance as insufficient information on the nature and benefits of GM foods is available to the public. ${ }^{2,3}$ Even in the USA which is the largest producer of GM foods, consumers' knowledge of the product is known to be generally low. ${ }^{4,5,7}$ In 2004, up to a quarter of Americans said they had neither heard of GM foods nor tasted them and $43 \%$ were not aware that GM foods were in the market. ${ }^{5}$ Yet over $90 \%$ of cotton and corn in the American markets are genetically modified. ${ }^{5}$ Over $70 \%$ of consumers believe that GM foods carry more risks than benefits and therefore are dangerous for consumption. ${ }^{8,9}$ In developing countries the awareness of GM foods is also poor with a perception of high risk in Kenya and Nigeria.

Medical doctors occupy a critical position of influence in the society by virtue of their knowledge and practice. If they are well informed about GM foods, this will cascade to better knowledge for members of the general public who encounter them during consultations or other fora. Studies on the knowledge of GM foods among this group of professionals are few in our environment. However, studies among undergraduate nursing students in Turkey and medical and dental students in Nigeria showed low levels of awareness and negative risk perceptions. ${ }^{8,11}$ Studies among medical doctors elsewhere showed, awareness level as low as $22 \%$ with up to $80 \%$ believing that GM foods were harmful. ${ }^{12}$ Findings from this study will provide baseline data against which to compare the outcome of subsequent interventions to improve the knowledge and perception of GM foods among the target group. The objective of this study was to assess the knowledge and perceptions of GM foods among medical doctors in a tertiary hospital in Nigeria.

\section{Methods}

The study was carried out in Jos University Teaching Hospital (JUTH) which is situated in Jos North Local Government Area (LGA) of Plateau State in Nigeria. Jos North is one of the 17 LGAs of Plateau State. It is the most cosmopolitan LGA in the State, being the LGA with the state capital. It is therefore well served with educational, social, health and physical infrastructures. JUTH is a federal tertiary hospital engaged in the training of undergraduate and postgraduate medical doctors in various areas of specialization of medicine. It is also involved in clinical services, research work and training of other healthcare professionals. Like other teaching hospitals in the country, most of the doctors practising in Plateau State are in the employment of JUTH. The hospital has the most highly trained collection of doctors in the state spread across 17 clinical departments.

From unpublished administrative data in the hospital, JUTH had 560 medical doctors in her employment at the time of the study, made up of 170 specialist consultants, 340 registrars undergoing 
postgraduate residency training and 50 house officers undertaking internship training. All of them constituted the study population. All doctors working in the Hospital were eligible to be included in the study. However, those who were on leave during the period of the study and therefore unavailable to provide data were excluded. The study used a cross sectional descriptive design and the minimum sample size was determined to be 214 using the formula for sample size determination in a cross sectional study. ${ }^{13}$ In this formula we used $16.7 \%$ as level of good knowledge as obtained from a similar study done in Lagos. ${ }^{11}$ In order to make up for a non-response $10 \%$ of the minimum sample size was added to arrive at a sample size of 235 studied.

The respondents were stratified according to the three cadres of medical doctors in the hospital; consultants, registrars and house officers. Proportionate-to-size allocation of the sample size was done for each cadre to arrive at 71,143 and 21 sampling units for consultants, registrars and house officers respectively. Each allocated size was then selected from a sampling frame for that cadre using simple random sampling technique with the aid of computer-generated random numbers.

Data collection by trained resident doctors from the Department of Community Medicine of JUTH took place in May 2018 using a semi-structured, self-administered questionnaire which was adapted from a similar study in Kenya. ${ }^{9}$ The collected data were analysed using the Statistical Package for Social Sciences (SPSS) computer software version $23 .{ }^{14}$ Sociodemographic characteristics of respondents and their knowledge and perceptions about GM foods were presented using frequency tables. Respondents' subjective self-rated knowledge was categorized as very bad, bad, average, good and very good. In addition, an objective knowledge score was computed for each respondent. A score of $50 \%$ or more of the total obtainable score was classified as good while a score below this was regarded as poor. Multiple logistic regressions were used for this dichotomous knowledge outcome to determine predictors of good knowledge among the socio-demographic characteristics. A $p$ - value of $\leq 0.05$ was considered statistically significant. Ethical approval for the study was obtained from the Health Research Ethics Committee of the Jos University Teaching Hospital. In addition, written informed consent was obtained from the respondents before their enrolment in the study.

\section{Results}

A total of 230 respondents completed and returned the study questionnaire giving a response rate of $97.9 \%$. The respondents' age range was 25-54 years and mean age $34.3 \pm 4.7$ years with $96.5 \%$ of them aged 25 - 44 years. One hundred and seventy seven $(77.0 \%)$ respondents were males, $69.6 \%$ were married and $80.0 \%$ were resident doctors. Doctors in the nonsurgical specialties constituted $53.0 \%$ of the respondents. A third $(30 \%)$ of the respondents had put in more than 10 years of practice post-graduation as shown in Table 1.

One hundred and seventy five (76.5\%) respondents rated their knowledge of GM foods to be either average, good or very good. However, objective knowledge assessment revealed that only $19.5 \%$ of them had good knowledge of GM foods (Table 2). In Table 3, one hundred and nineteen ( $51.7 \%)$ respondents acknowledged consuming GM foods though $87.0 \%$ expressed some concern. The most common concern was related to the effect of GM foods on human health 
(47.0\%). One hundred and twenty four $(53.9 \%)$ said they would recommend GM foods to someone whereas $31.7 \%$ indicated current willingness to consume GM foods. On logistic regression, respondents who had practised for less than ten years post-graduation were two and a half times more likely to have good knowledge score on GM foods compared to those who had practised for ten years or more $(\mathrm{p}=0.041)$. Age, sex, staff cadre and marital status were not statistically significant predictors of good knowledge of GM foods among the respondents (Table 1).

Table 1: Predictors of good knowledge of GM foods among doctors

\begin{tabular}{|c|c|c|c|c|c|}
\hline \multirow{4}{*}{$\begin{array}{l}\text { Variable } \\
\text { Age (years) }\end{array}$} & \multicolumn{2}{|c|}{ Knowledge $\quad n=230$} & \multirow{4}{*}{$* * \mathbf{O} . \mathbf{R}$. } & \multirow{4}{*}{ +C. I. of OR } & \multirow{4}{*}{ p-value } \\
\hline & Good & Poor & & & \\
\hline & Freq.(\%) & Freq.(\%) & & & \\
\hline & & & & & \\
\hline $25-34$ & $31(68.9)$ & $102(55.1)$ & 0.683 & 0.0805 .824 & 0.728 \\
\hline $35-44$ & $11(24.4)$ & $78(42.2)$ & 0.463 & $0.054-3.978$ & 0.483 \\
\hline $45-54$ & $3(6.7)$ & $5(2.7)$ & 1 & & \\
\hline \multicolumn{6}{|l|}{ Sex } \\
\hline Male & $37(82.2)$ & $140(75.7)$ & 0.591 & $0.287-1.224$ & 1.219 \\
\hline Female & $8(17.8)$ & $45(24.3)$ & 1 & & \\
\hline \multicolumn{6}{|l|}{ Marital status } \\
\hline Ever married* & $31(68.9)$ & $131(70.8)$ & 0.306 & $0.0685-0.332$ & 1.414 \\
\hline Single & $14(31.1)$ & $54(29.2)$ & 1 & & \\
\hline \multicolumn{6}{|l|}{ Cadre } \\
\hline Consultant & $5(11.1)$ & $16(8.6)$ & 1.011 & $0.259-3.939$ & 0.988 \\
\hline Resident doctor & $34(75.6)$ & $150(81.1)$ & 1.393 & $0.517-3.751$ & 0.512 \\
\hline House officer & $6(13.3)$ & $19(10.3)$ & 1 & & \\
\hline \multicolumn{6}{|c|}{ Broad specialty area } \\
\hline Surgical & $14(31.1)$ & $94(50.8)$ & 1.536 & $0.789-2.959$ & 0.199 \\
\hline Medical & $31(68.9)$ & $91(49.2)$ & 1 & & \\
\hline \multicolumn{6}{|c|}{ Years post-graduation } \\
\hline$<10$ & $31(68.9)$ & $130(70.3)$ & 2.567 & $1.293-5.096$ & 0.041 \\
\hline$=10$ & $14(31.1)$ & $55(29.7)$ & 1 & & \\
\hline
\end{tabular}

* Ever married combines those currently married and those married before but were divorced at the time of the study.

$* *$ O.R. $=$ Odds ratio. + C.I. Confidence interval

Table 2: Knowledge of GM foods among medical doctors $(\mathrm{n}=\mathbf{2 3 0})$

\begin{tabular}{lr}
\hline Variable & Freq. (\%) \\
\hline Self-rated knowledge & \\
Very bad & $5(2.2)$ \\
Bad & $49(21.3)$ \\
Average & $142(61.7)$ \\
Good & $25(10.9)$ \\
Very good & $9(3.9)$ \\
Assessed knowledge & \\
Good & $45(19.5)$ \\
Poor & $185(80.5)$ \\
\hline
\end{tabular}


Table 3: Perception and acceptance of GM foods among medical doctors $(n=230)$

\begin{tabular}{lr}
\hline Variable & Freq.(\%) \\
\hline Has consumed GM foods before & \\
Yes & $119(51.7)$ \\
No & $111(48.3)$ \\
Willingness to recommend GM foods & to someone \\
Yes & $124(53.9)$ \\
No & $106(46.1)$ \\
Concerns about GM foods & \\
Yes & $200(87.0)$ \\
No & $30(13.0)$ \\
Fears about GM foods & \\
Health concerns (cancer, allergies, obesity, mutation) & $108(47.0)$ \\
Cost (expensive) & $4(1.7)$ \\
No fears & $32(13.9)$ \\
Not stated & $86(37.4)$ \\
Willingness to consume GM foods & \\
Very willing & $26(11.3)$ \\
Somewhat willing & $47(20.4)$ \\
Undecided & $53(23.0)$ \\
Somewhat reluctant & $69(30.0)$ \\
Very reluctant & $35(15.3)$ \\
\hline
\end{tabular}

\section{Discussion}

Although majority of the respondents rated their knowledge of GM foods to range from average to very good, an objective assessment of knowledge revealed that majority of them knew very little about GM foods. Only one out of every 5 had a score adjudged as good knowledge on GM foods. A similar study among medical doctors in Turkey also revealed that more than half of the respondents expressed their knowledge as either average, good or very good, yet less than a quarter of them were adjudged to have good knowledge scores. ${ }^{12}$ Similarly, only a small proportion of undergraduate medical and dental students in Lagos, Nigeria had a score considered to be good knowledge of GM foods. ${ }^{11}$ In Turkey, knowledge levels among undergraduate nursing students were also adjudged to be poor. ${ }^{8}$ These gaps between the levels of self-rated knowledge and assessed knowledge may explain the existence of misconceptions, half-truths and myths about GM foods among the study population. They highlight the need for the provision of comprehensive information and education on GM foods to all consumers of the product. It means the knowledge of many doctors on GM foods is largely incorrect. This does not help knowledge development among the public if this critical group of health professionals who are expected to be a credible source of information are themselves, not knowledgeable about the subject. Patients expect that all the information provided to them by doctors in the course of clinical consultation and counselling on all health related matters are factual. ${ }^{15}$

A high proportion of the respondents expressed concerns over health risks that could arise from the consumption of GM foods. This level of concern has the potential to spiral into negative attitudes towards GM foods among members of the public. In another study, a similarly high proportion of medical doctors stated that GM foods were harmful. ${ }^{12}$ Furthermore, as 
high as $70 \%$ of nursing students thought that the production of GM foods carried along with it a health risk and was dangerous for consumption and therefore disapproved of its use. ${ }^{8}$ However, the proportion of medical and dental students believing there were potential health risks associated with GM foods was less than this figure. ${ }^{11}$ The difference in risk perception between medical doctors and medical students could be explained by the fact that doctors are more knowledgeable than the students in the theory of bioengineering and the potentials for mutations in GMOs and GM foods. ${ }^{12}$ They are likely to be more circumspect about the safety of the products than the students whose knowledge is probably more superficial. A survey of food consumers in Enugu, Nigeria revealed that more than half of the respondents believed that GM foods were harmful to health and their level of risk perception was lower than what our study revealed. ${ }^{10}$ The heterogeneity of the population in that study meant the group comprised of individuals with varying socio-economic backgrounds and levels of awareness and knowledge about GM foods which are significantly different from those in this study.

Only a third of the respondents in this study indicated a willingness to consume GM foods. Such a small number is a reflection of a perception of significant health risks demonstrated by the respondents. A study among nursing students showed an even lower proportion of the participants expressing their willingness to consume GM foods. ${ }^{8}$ In contrast, over half of academics in Polish universities indicated support for the use of GMOs in food production which implied a probable willingness to consume GM foods. ${ }^{16}$ Among the consumers in Enugu, over half of them were also willing to consume GM foods even though this survey was among members of the general public. ${ }^{10}$ Such positive predisposition towards GM foods is explained by the relatively lower perception of health risks that was demonstrated in this category of respondents. ${ }^{10}$ The risk perception by respondents could also be a function of their sources of information about GM foods as these have been reported to vary widely. ${ }^{16}$

In this study, the younger doctors who had put in less than ten years of practice were two and a half times more likely to have good knowledge scores compared to their older counterparts who had worked for ten years or more. Most of these younger doctors are in postgraduate residency training programs which require their studying widely for examinations. They probably acquired the knowledge of GM foods in the course of their studies. In addition, the technology of genetic modification of foods is relatively new. ${ }^{1,2,17}$ The older doctors may not be conversant with this development as it emerged when most of them were already out of school. Most of the literature on GM foods is only in the internet and the younger generation are more internet savvy than the older ones. ${ }^{17}$ A study among medical and dental students in Lagos Nigeria, the only factors that were found to significantly influence their knowledge on GM foods were gender and their course of study. ${ }^{11}$

The findings from this study highlight the need for continued comprehensive dissemination of scientifically sound information about GM foods to members of the public especially doctors who have been found to be inadequately informed about the foods. In addition, environmental and public health concerns about GM foods should not be discountenanced but continuously researched into on a long term basis so that possible deleterious effects of the foods, if 
any, can be detected early and mitigated.

\section{Conclusion}

This study shows that knowledge of GM foods is poor among doctors in JUTH and they believe that the concerns about the negative effects of GM foods on human health, the environment and biodiversity are real. They are therefore unwilling to consume GM foods. As frontline educators, it is recommended that medical doctors be specifically targeted with relevant education to increase their knowledge and change their negative perception towards GM foods. It is also important to incorporate the subject of biotechnology into the teaching curriculum of undergraduate medical students since this is a relatively new and evolving field.

\section{References}

1. Zhang C, Wohlhueter R, Zhang H. Genetically modified foods: A critical review of their promise and problems. Food Sci Hum Wellness (Internet). 2016; 5(3):116-23.

Available from http://dx.doi.org/10.1016/j.fshw.201 6.04.002

2. World Health Organisation.

Frequently asked questions on genetically modified foods in WHO health topics: food safety (Internet). Geneva: WHO; 2014 (cited 2018 November). Available from: http://www.who.int/foodsafety/area s_work/food-technology/faqgenetically-modified-food/en/

3. Bett EK, Nyairo N, Ayieko DMO, Amolo JO. Determinants of consumer perception towards genetically modified foods in higher learning institutions in Kenya. Journal of Economics and Sustainable Development 2014; 5(24):35-44
4. Hallman W, Hebden W, Cuite C, Aquino H, Lang J. Americans and GM food: knowledge, opinion \& interest in 2004. New Brunswick (NJ): Rutgers, the State University of New Jersey, Food Policy Institute; 2004 Nov Report No. RR1104-007

5. Hallman WK, Cuite CL, Morin XK. Working paper 2013-1: Public perceptions of labelling genetically modified foods. New Brunswick (NJ): Rutgers, the State University of New Jersey, School of Environmental and Biological Sciences 2013 Nov. Available from: http://humeco.rutgers.edu

6. Herrera LR. Genetically Modified Crops and Developing Countries. Plant Physiol 2018; 124:923-925

7. Jurkiewicz A, Zagorski J, Bujak F, Lachowski S, Florek-Luszczki M.

Emotional attitudes of young people completing secondary schools towards genetic modification of organisms (GMO) and genetically modified foods (GMF). Ann Agric Environ Med 2014; 21:205-11

8. Turker T, Kocak N, Aydin I, Istanbulloulu $\mathrm{H}$, Yildiran N, Turk YZ, Kilic S. Determination of attitude, knowledge and behavior about genetically modified organisms in nursing school students. Gulhane Tip Derg 2013; 55:297-304

9. Keneth KK. Assessment of public perception, awareness and knowledge on genetically engineered food crops and their products in Trans-Nzoia county, Kenya. J Dev Sus Agr 2011; 6(2):164-180

10. Eneh OC, Eneh CA, Chiemela SN. Food consumer perception of genetically modified foods in 
Enugu metropolis, Nigeria. Jokull 2016; 66(4):1-16

11. Ebuehi MO, Ailohi OL. Genetically Modified (GM) Foods/Organisms: Perspectives: Perspectives of undergraduate medical and dental students of the College of Medicine, University of Lagos, Nigeria. Food and Public Health 2012; 2(6): 281-295

12. Hassan BS, Faith G, Duygu KD, Omer O, Mesut G, Hilal D. Medical doctors' perceptions of genetically modified foods (Internet). Journal of Clinical and Analytical Medicine 2014 (cited 2018 Nov). Available from: www.jcam.com.tr/files/KATD-2639

13. Kirkwood BR, Sterne JA.

Calculation of required sample size in: Essential Medical Statistics. Massachusetts; Blackwell Science Ltd. $2^{\text {nd }}$ ed 2003:413-428

14. Industrial Business Machines
Corporation. Industrial Business Machines Statistical package for Social Science: Statistics for Windows version 23.0. Armonk, NY: IBM Corp. 2016:413-428

15. Wunderlich S, Gatto KA. Consumer perception of Genetically Modified Organisms and sources of information. Adv Nutr. 2015; 6(6): 842-851

16. Malyska A, Maciag K, Twardowski T. Perception of GMOs by scientists and practitioners - the critical role of information flow about transgenic organisms. New Biotechnology 2014; 31(2):196202. Available from: http://doi.org/10.1016/j.nbt.2013.11 .004 .

17. Bawa AS, Anilakumar KR.

Genetically modified foods: safety, risks and public concerns- a review. J Food Sci Technol.2013; 50(6):1035-1046 